\title{
Conservation in Function of a SCAR/WAVE Component During Infection Thread and Root Hair Growth in Medicago truncatula
}

\author{
Akira Miyahara, ${ }^{1}$ Jennifer Richens, ${ }^{1}$ Colby Starker, ${ }^{2}$ Giulia Morieri, ${ }^{3}$ Lucinda Smith, ${ }^{2}$ Sharon Long, ${ }^{2}$ \\ J. Allan Downie, ${ }^{3}$ and Giles E. D. Oldroyd ${ }^{1}$ \\ ${ }^{1}$ Department of Disease and Stress Biology, John Innes Centre, Norwich Research Park, Colney Lane, Norwich, NR4 7UH, \\ U.K.; ${ }^{2}$ Department of Biological Sciences, Stanford University, Stanford, CA 94305, U.S.A.; ${ }^{3}$ Department of Molecular \\ Microbiology, John Innes Centre, Norwich Research Park, Colney Lane, Norwich, NR4 7UH, U.K.
}

Submitted 7 July 2010. Accepted 7 August 2010.

\begin{abstract}
Nitrogen-fixing symbioses of plants are often associated with bacterially infected nodules where nitrogen fixation occurs. The plant host facilitates bacterial infection with the formation of infection threads, unique structures associated with these symbioses, which are invaginations of the host cell with the capability of traversing cellular junctions. Here, we show that the infection thread shares mechanistic similarities to polar-growing cells, because the required for infection thread (RIT) locus of Medicago truncatula has roles in roothair, trichome, and infection-thread growth. We show that RIT encodes the M. truncatula ortholog of NAP1, a component of the SCAR/WAVE (suppressor of cAMP receptor/ WASP-family verprolin homologous protein) complex that regulates actin polymerization, through the activation of ARP2/3. NAP1 of Arabidopsis thaliana functions equivalently to the $M$. truncatula gene, indicating that the mode of action of NAPI is functionally conserved across species and that legumes have not evolved a unique functionality for NAP1 during rhizobial colonization. This work highlights the surprising commonality between polar-growing cells and a polar-growing cellular intrusion and reveals important insights into the formation and maintenance of infectionthread development.
\end{abstract}

The legume-rhizobial symbiosis is an agronomically important process in which molecular dinitrogen is converted to ammonia by rhizobial symbionts and supplied to the host plant in exchange for a carbon source. Biological nitrogen fixation within this symbiosis necessitates the invasion of the host root by the bacteria to allow symbiosome formation: a differentiated form of the rhizobial bacteria contained within a mem-

\section{A. Miyahara and J. Richens contributed equally to the work.}

Current address of J. Richens: Sir William Dunn School of Pathology, University of Oxford, South Parks Road, OX1 3RE, U.K.

Current address of C. Starker: Department of Plant Biology, University of Minnesota, 1445 Gortner Ave., St. Paul, MN 55108, U.S.A.

Corresponding author: G. Oldroyd; Telephone: +1603 450206; E-mail: giles.oldroyd@bbsrc.ac.uk

The MtNAP1 nucleotide sequence reported in this article has been submitted to the GenBank with accession number HM590708.

* The $\boldsymbol{e}$-Xtra logo stands for "electronic extra" and indicates that three supplementary tables and two supplementary figures are published online. brane-bound compartment of cells in nodules where nitrogen fixation occurs.

Bacterial invasion of the host root is facilitated by plant-derived infection threads: tube-like invaginations of the host cell with the capability of traversing cell junctions. Infection threads are initiated following rhizobial attachment to root-hair cells and the localized production of the rhizobial-made Nod factor signaling molecule. This induces deformation of root hairs, with the root-hair tip growing around the attached bacteria, leading to entrapment of the bacteria within a root-hair curl (Esseling et al. 2003). Once a microcolony is entrapped, infection threads are initiated. Bacteria divide within the infection thread that grows into the root cortex and, thus, bacteria gain access to the developing nodule that is initiated below the site of infection.

Plant perception of a Nod factor is a critical first step in the initiation of the legume-rhizobial symbiosis. The Nod factor signal transduction pathway has been well characterized, as have some of the processes required for nodule initiation (Oldroyd and Downie 2008). However, the mechanisms involved in bacterial invasion and, in particular, infection-thread formation are poorly understood. It has long been hypothesized that the plant requires a high degree of stringency for Nod factor recognition in order to initiate bacterial infection (Ardourel et al. 1994). This is the function of a specific Nod factor receptor, and the Medicago truncatula HCL gene, that encodes the LYK3 receptor-like kinase, is a likely candidate (Limpens et al. 2003; Smit et al. 2007).

Several additional loci have been described that are necessary for infection-thread initiation and growth. M. truncatula $R P G$, that encodes a nuclear-localized protein with coiled-coil domains, is required for normal infection-thread growth; rpg mutants have aborted and thickened infection threads, containing many protrusions, as well as showing defects in initial roothair curling (Arrighi et al. 2008). The M. truncatula gene LIN, and CEBERUS, its ortholog in Lotus japonicus, encode E3 ubiquitin ligases with essential functions in bacterial infection (Kiss et al. 2009; Yano et al. 2009). Several loci have been described in L. japonicus that are necessary for rhizobial infection, including CRINKLE, LOT1, LjSYM40, and LjSYM67 (Ooki et al. 2005; Sandal et al. 2006; Tansengco et al. 2003, 2004), which are also required for appropriate trichome development; and crinkle, sym40, and sym67 cause additional defects in roothair development (Tansengco et al. 2003, 2004). This suggests common genetic mechanisms between infection-thread, trichome, and root-hair development. LjSYM40 and LjSYM67 encode 
the L. japonicus orthologs of NAPI and PIRI (Yokota et al. 2009) that are involved in actin rearrangements in Arabidopsis thaliana (Li et al. 2004; Szymanski 2005).

Here, we describe the identification and characterization of $M$. truncatula required for infection threads (RIT). Plants mutated in RIT show aborted infection threads with extensive protrusions. Occasional nodules develop on rit-1 mutants but these show lower levels of rhizobial colonization. Similar to loci described in L. japonicus that are necessary for infection-thread development, RIT is also necessary for appropriate trichome and root-hair development. RIT encodes the M. truncatula orthologue of $N A P 1$, placing it as part of the SCAR/WAVE (suppressor of cAMP receptor/WASP-family verprolin homologous pro-
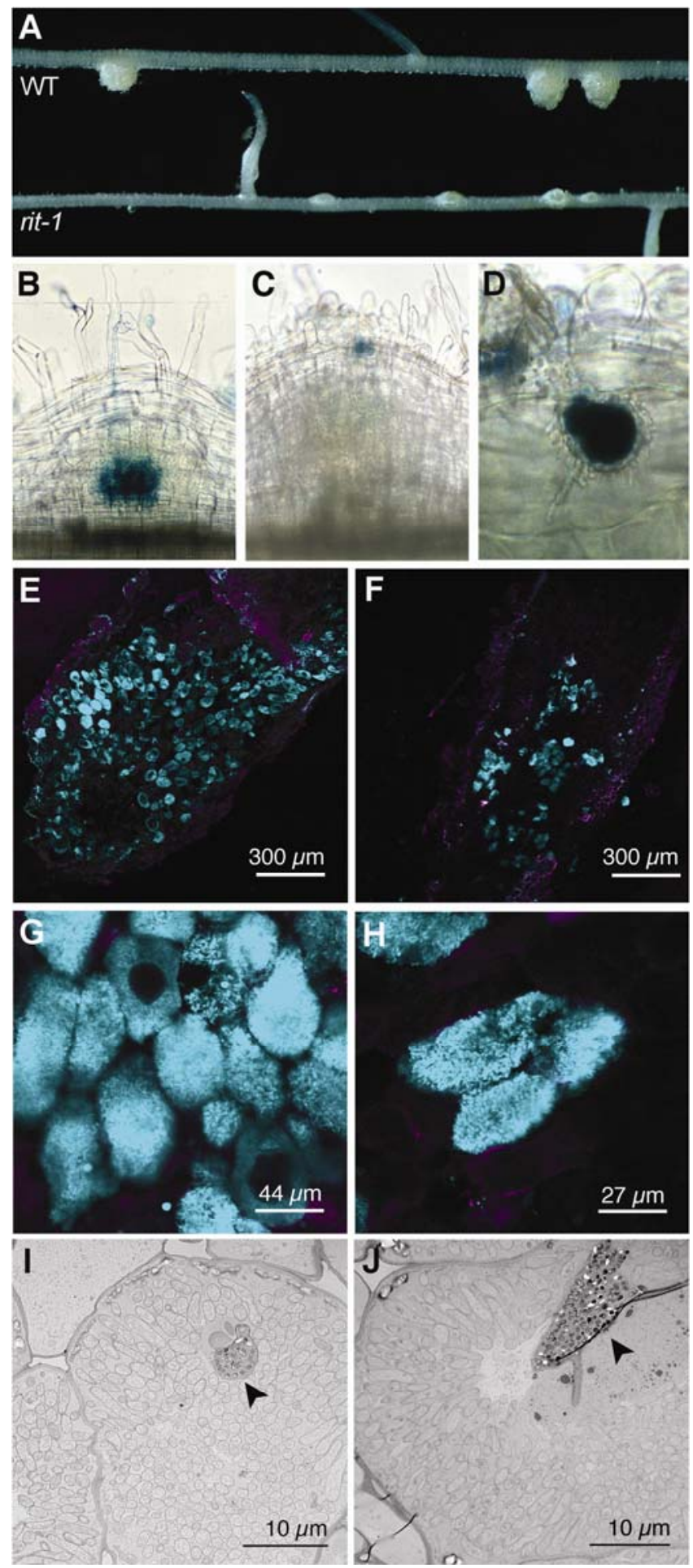

tein) complex responsible for controlling polymerization of actin-related proteins. The rit- 1 mutant can be functionally complemented by NAPI from A. thaliana, revealing common mechanisms of action across these species, even in a process not present in A. thaliana. This work reveals the essential role of actin rearrangements during the maintenance of infection-thread development and further shows that common mechanisms underlie polar growth of root-hair and trichome cells and the polargrowing cellular intrusions that are infection threads.

\section{RESULTS}

\section{A novel M. truncatula locus required} for nodule development.

In a screen of fast-neutron mutagenized M. truncatula, several nodulation-defective mutants were identified. We chose to focus on one such mutant that showed reduced nodulation, with small bumps developing on the roots in place of fully developed nodules after inoculation with the M. truncatula symbiont Sinorhizobium meliloti (Fig. 1A). This mutation segregated as a single recessive locus, because 25 of 125 segregating plants showed a mutant phenotype, indicative of a 3:1 segregation $\left(\chi^{2}\right.$ $P$ value $=0.264)$. Preliminary allelism tests indicated a novel locus, and this was validated with mapping and cloning (described later). For reasons described below, this locus was called RIT. A detailed phenotypic analysis was performed on the mutant lines after backcrossing twice to wild-type plants.

\section{$R I T$ is required for normal infection-thread growth.}

The rit-1 mutant shows greatly reduced levels of nodulation compared with wild-type plants (Table 1), and limited nodule development (Fig. 1A). To test whether this was a result of a defect in infection-thread development, wild-type and rit-1 plants were inoculated with $S$. meliloti carrying a constitutive lac $Z$ reporter, allowing ease of visualization of infection threads. Seven days after inoculation, wild-type plants showed extended infection threads ramifying into the developing nodule primordium (Fig. 1B). In contrast, rit-1 plants showed infec-

Table 1. Nodulation and acetylene reduction in rit-1 mutants ${ }^{\mathrm{a}}$

\begin{tabular}{lcccccc}
\hline & \multicolumn{2}{c}{ Nodule number } & & \multicolumn{2}{c}{$\begin{array}{c}\text { Actylene reduction activity } \\
\left(\mathbf{n m} \text { of ethylene } \mathbf{h}^{\mathbf{1}} \text { ) }\right.\end{array}$} \\
\cline { 2 - 3 } \cline { 5 - 6 } Genotype & $\mathbf{2 1 ~ d p i}$ & $\mathbf{3 5} \mathbf{~ d p i}$ & & $\mathbf{2 2} \mathbf{~ d p i}$ & $\mathbf{3 5 ~ d p i}$ \\
\hline Wild type & $26.0 \pm 11.27$ & $72 \pm 5.5$ & & $26.9 \pm 10.5$ & $13.7 \pm 12.3$ \\
rit-1 & $10.4 \pm 4.82$ & $16 \pm 8.2$ & & 0 & $5.1 \pm 4.0$ \\
\hline
\end{tabular}

${ }^{a}$ Errors indicate standard deviations. Acetylene reduction assays were carried out on nodules, with a comparable nodule number and nodule fresh weight between samples; dpi = days postinoculation.

Fig. 1. Medicago truncatula Required For Infection Thread (RIT) is required for rhizobial infection. M. truncatula plants grown on plates were inoculated with Sinorhizobium meliloti hemA-lacZ (that allows visualization of infection threads by staining for $\beta$-galactosidase activity). A, Wildtype and rit- 1 roots 20 days postinoculation. $\mathbf{B}$ through $\mathbf{D}$, At 7 days after inoculation, $\mathbf{B}$, infection threads had traversed the root cortex in wild-type plants but $\mathbf{C}$, appear to have aborted in the root epidermis and outer cortex in rit-1. Detailed analysis of an arrested infection thread shown in D: the basal part of a root-hair cell in rit- 1 revealed swollen infection-thread tips with many protrusions, suggestive of new attempts to initiate the infection thread. E through H, SYTO13 staining of nodules, 35 days postinoculation with $S$. meliloti on soil-grown $M$. truncatula plants, revealed diffuse bacterial colonization of rit- 1 nodules. $\mathbf{E}$ and $\mathbf{G}$, Wild type; $\mathbf{F}$ and $\mathbf{H}$, rit- 1 . $\mathbf{I}$ and $\mathbf{J}$, Transmission electron microscopy of infected cells of nodules on soil-grown plants 35 days after inoculation. I, wild type; J, rit-1. Note the expanded infection thread in rit- 1 compared with the wild type, indicated with arrowheads. 
tion threads restricted to epidermal root-hair cells, despite the underlying development of a nodule primordium (Fig. 1C). Closer inspection of these apparently aborted infection events revealed swollen and deformed infection threads (Fig. 1D) contained within the root-hair cells. The infection events that formed in rit- 1 were restricted to root-hair cells and we saw no evidence for rhizobial entry through cracks in the root epidermis. However, 35 days postinoculation (dpi), soil-grown rit-1 plants developed some large nodules (Table 1). These nodules had low levels of nitrogenase activity in contrast to nodules on wild-type plants (Table 1). SYTO13 staining (a fluorescent nucleic acid dye that predominantly stains bacteria in the nodule) revealed that the nodules that developed on rit- 1 at 35 dpi were sparsely infected with rhizobia, with patches of infected cells (Fig. 1F), compared with wild-type nodules, in which most cells within the nitrogen-fixation zone of the nodule were filled with bacteroids (Fig. 1E). The infected cells of rit-1 nodules appeared normal (Fig. $1 \mathrm{H}$ and $\mathrm{J}$ ), with elongated bacteroids, reminiscent of the wild type (Fig. 1G and I). However, infection threads within these rit-1 nodules were greatly enlarged (Fig. 1J) compared with infection threads in wildtype nodules (Fig. 1I). From this work, we conclude that RIT is essential to sustain normal infection-thread growth. After a long period of colonization, the rit- 1 mutant can accommodate some bacteria in nodules; however, infection threads ramifying within these rit- 1 nodules still showed the distended phenotype observed at earlier stages of colonization.

Although RIT has a clear role in rhizobial infection, the fact that nodule primordia do develop (Fig. 1C) suggested that RIT does not have a role in nodule organogenesis. To validate this hypothesis, we transformed rit-1 roots with the CCaMK gainof-function that activates spontaneous nodule formation in the absence or rhizobial colonization (Gleason et al. 2006). We observed spontaneous nodules developing on both wild-type and rit- 1 mutants, indicating that $R I T$ is not required for nodule organogenesis.

\section{The Nod factor signaling pathway is unaffected in rit-1.}

One possible scenario for the defects observed in rit- 1 is a defect in the Nod factor signaling pathway. We used two assays, Nod-factor-induced calcium spiking and gene expression, to assess Nod factor signaling in rit-1. Microinjection of rit-1 root-hair cells with the calcium-responsive dye Oregon Green revealed normal calcium spiking in response to Nod factor in rit-1 (Supplementary Fig. 1A). To assess Nod-factorinduced gene expression we used the ENOD11 promoter- $\beta$ glucuronidase (GUS) fusion (Journet et al. 2001) that was crossed into the rit-1 mutant. Wild-type ENOD11-GUS and rit1 ENOD11-GUS seedlings were treated with $10^{-9} \mathrm{M}$ Nod factor and the levels of GUS activity quantified using methyl umbelliferyl glucuronide. GUS activity was equivalent in wildtype and rit-1 plants. The spatial pattern of ENOD11-GUS also remained unchanged in the rit-1 mutant (data not shown). Taken together, the calcium-spiking and gene-expression assays indicate that RIT does not function in Nod-factor signaling.

\section{$R I T$ is also required}

\section{for trichome, root-hair, and seed-coat development.}

Gene rit- 1 was identified due to its defects in nodulation but, during the characterization of this mutant, we observed additional developmental defects. Root hairs in rit-1 are shorter than those on wild-type roots (Fig. 2A and B), with root hairs on rit-1 appearing slightly swollen; this is particularly pronounced toward the base of the root hairs. Consistent with our observations on Nod-factor signaling in rit-1, root hairs of rit-1 responded to Nod factor with branching and deformed growth (data not shown), indicating normal responses to Nod factor. Trichomes on the leaves of rit- 1 were noticeably shorter, and this was apparent from visual inspection (Fig. $2 \mathrm{C}$ and D). Scanning electron microscopy showed that the trichomes of rit-1 were distinctly shorter and distorted relative to trichomes on wild-type plants (Fig. 2E and F). In addition, we observed seed-coat defects that were initially apparent as an enhanced sensitivity to
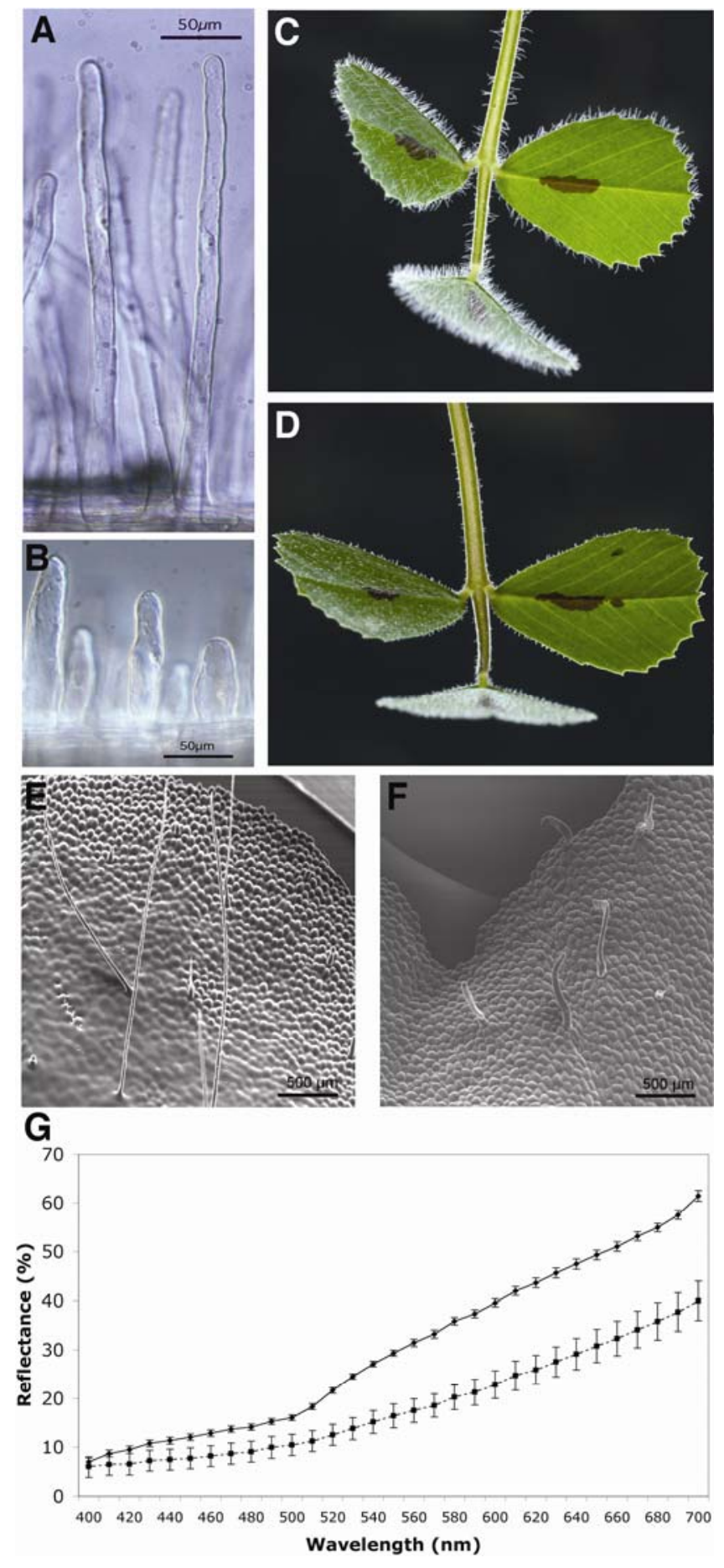

Fig. 2. Nonsymbiotic phenotypes of rit-1. The rit-1 mutants showed defects in root hairs, trichomes, and the seed coat. Both root hairs and trichomes of rit- 1 are reduced in length: $\mathbf{A}$, root hairs on a wild-type plant; $\mathbf{B}$, root hairs on a rit- 1 plant. The trichome defect is apparent from macroscopic analysis of the leaf: $\mathbf{C}$, wild type; D, rit-1; and from a scanning electron micrograph: E, wild type; $\mathbf{F}$, rit-1. G, In addition, rit-1 shows reduced reflectance of the seed coat. The graph shows the percentage reflectance of seed at 400 to $700 \mathrm{~nm}$. The solid line indicates measurements made with wild-type seed and the broken line with rit- 1 seed. 
sulfuric acid, which we were using as a means of seed-coat scarification; the mutant seed were usually killed by treatment with concentrated sulfuric acid for $5 \mathrm{~min}$ whereas wild-type seed normally survived this treatment. This enhanced acid sensitivity may be related to the observation that the rit- 1 seed coat was darker than that of wild-type seed (Fig. 2G). This implies that the rit- 1 seed coat has a different profile of components that affect both color and function. The infection-thread, trichome, root-hair, and seed-coat phenotypes all remained in key recombinants from our positional cloning work (described later), where crossovers existed on both sides of RIT; furthermore, the trichome, root-hair, and infection-thread defects cosegregated in a backcrossed population, indicating that all the phenotypes are a function of rit-1. Considering the necessity of RIT to sustain polar-growing structures, we also assessed pollen tube growth. Germinated pollen tubes from rit-1 did not show differences in growth or development relative to pollen tubes from wild-type plants (data not shown) and reciprocal crosses revealed no differences in fertility of rit- 1 pollen. We conclude that RIT has a central role in some polar-growing structures (trichomes, root hairs, and infection threads) as well as a role in appropriate seed-coat composition.

\section{Map-based and transcript-based cloning identified a chromosomal rearrangement in rit-1 between chromosomes 3 and 4 .}

Initial genetic mapping in an A20/rit-1 segregating population that focused on mutant individuals indicated that RIT cosegregated with markers on the lower arm of chromosome 3 (Supplementary Fig. 2A). In this rit- $1 \times \mathrm{A} 20 \mathrm{~F}_{2}$ population, we observed that the segregation of the mutant phenotype was 9:1 wild type/mutant (788:87 wild type/mutant, with a $\chi^{2} P$ value $<$ 0.0001 based on a null hypothesis of $3: 1$ segregation). At this stage, we were unable to explain this distorted segregation; however, normal pollen-tube germination in rit- 1 suggested that it was not a gametophytic effect. In order to rule out gametophytic affects on the segregation ratio, we performed test crosses (Supplementary Table 1). We constructed a physical map of the region on chromosome 3 where RIT appeared to reside, starting with the bacterial artificial chromosome (BAC) Mth2-2214, which contained the marker DK313L, which cosegregated $100 \%$ with the mutant phenotype. As sequence data for BAC in the physical map became available, the web-based simple satellite repeat (SSR) identification tool SSRit (Temnykh et al. 2001) was used to identify SSR within the sequence, and these were used to develop polymorphic markers between A17 and A20. This allowed us to define the RIT region between the BAC Mth2-64c24 and Mth2-35n9, a region of $>600 \mathrm{~kb}$ that covered a mapping interval of approximately 0.1 centimorgan (cM). The normal physical distance in $M$. truncatula covered by $1 \mathrm{cM}$ has been estimated to be $470 \mathrm{~kb}$ (Thoquet et al. 2002). Thus, the unusually high ratio between the physical and genetic intervals in the RIT region indicated suppression of recombination. This was further complicated when we genetically analyzed the entire mapping population, including both mutant and wild-type plants. From this, we found several phenotypically wild-type individuals that showed genotypes indicative of a mutant. Based on these observations, we concluded that not only was there distorted segregation of the rit-1 mutation and suppression of recombination within the RIT region but there may also be a suppressor of the mutant phenotype in the mapping parent.

Considering the complexity of the positional cloning and our inability to further refine the physical region containing $R I T$, we chose to analyze the rit- 1 expression profile to identify genes within the RIT region whose expression was reduced compared with wild-type plants. We identified several transcripts that were greatly downregulated in mutant roots relative to wild-type roots in the absence of rhizobial treatment (Table 2). One was a signal peptidase (TC94661) that was present on the BAC Mth2-168g20, within the RIT region. Considering that rit-1 was isolated following fast neutron mutatagenesis, which often induces deletions, we used polymerase chain reaction (PCR) to assess the nature of the gene represented by TC94661 in rit-1. We were unable to use PCR across the $3^{\prime}$ untranslated region (UTR) of TC94661. DNA hybridization using a probe designed across this region (Fig. 3A) revealed both a larger fragment and the presence of an extra band in rit1 compared with the wild type (Fig. 3A), indicating that either an insertion or a rearrangement had taken place within the $3^{\prime}$ UTR of TC94661. There were a number of additional probe sets that were strongly downregulated in rit-1 (Table 2). These may represent additional mutated genes or they may be downregulated due to the absence of RIT. Considering the complexity of the mutation in rit-1 (described below), it seems likely that these may be additionally mutated genes.

Inverse PCR and DNA sequencing using primers to the $3^{\prime}$ UTR of TC94661 (Fig. 3C, no. 1) revealed that this region was contiguous with a region of chromosome 4 containing the $N A P 1$ gene. Inverse PCR from the NAPl gene on chromosome 4 using primers (Fig. 3C, no. 2) indicated that a region between Mth2-168g20 and Mth2-157g22 on chromosome 3 was inserted within the NAPl gene in rit-1, with one breakpoint lying within the $3^{\prime}$ UTR of TC94661. Furthermore, 6- and 417-bp deletions had occurred at the deletion-insertion points in chromosomes 3 and chromosome 4, respectively. Predictions of the newly formed HindIII digestion products from these rearrangements (Fig. 3C) were consistent with the sizes observed following DNA hybridization with HindIII-digested DNA from rit-1 (Fig. 3A). Reverse-transcription (RT)-PCR showed that this deletion-insertion rearrangement prevents production of mature NAPl mRNA, resulting in a truncated product in rit-1 (Fig. 3D).

The nature of the rit-1 mutation explained the problems we experienced in the positional cloning. The rearrangement could explain both the distorted segregation and the suppression of recombination within this region. The nature of the mutation also explains the apparent genetic suppressor. Although we were only analyzing the segregation of chromosome 3 markers, the actual segregation that was determining the segregation of wild type to mutant was on chromosome 4; thus, plants that appeared to be a genotypically homozygous mutant on chromosome 3 could be heterozygous for the NAPI

Table 2. Affymetrix probe sets downregulated in the rit-1 mutant

\begin{tabular}{lrrll}
\hline Probe set & $\mathbf{A 1 7}^{\mathbf{a}}$ & rit $^{\mathbf{a}}$ & Fold change & \multicolumn{1}{c}{ Expressed sequence tag number and predicted identity } \\
\hline Mtr.43153 & $5,565.76$ & 125.62 & -45.1 & TC94661, signal peptidase \\
Mtr.13046 & $1,429.01$ & 33.71 & -42.4 & TC96775, hypothetical protein 1 (predicted to be membrane localized) \\
Mtr.39994 & 138.53 & 6.94 & -19.95 & TC106254, similarity to immunoglobulin light chain \\
Mtr.34647 & 351.07 & 17.66 & -19.88 & BQ157958, calcium dependent protein kinase (CDPK) \\
Mtr.5098 & 422.35 & 27.07 & -15.6 & AW686896, hypothetical protein 1 (predicted to be membrane localized) \\
Mtr.9681 & 760.92 & 233.09 & -3.26 & TC104058, Nap1 \\
\hline
\end{tabular}

${ }^{a}$ Expression level in arbitrary units. 
gene on chromosome 4. The issues seen while mapping the rit-1 mutation highlight some of the potential drawbacks to mapping mutations caused by fast-neutron mutagenesis because complex rearrangements can, and do, occur.
The M. truncatula NAP1 gene.

The $M$. truncatula ortholog of NAP1 was identified from the BAC Mth2-138b18 sequence and its exon-intron structure was determined based on the full-length cDNA sequence of NAPl.
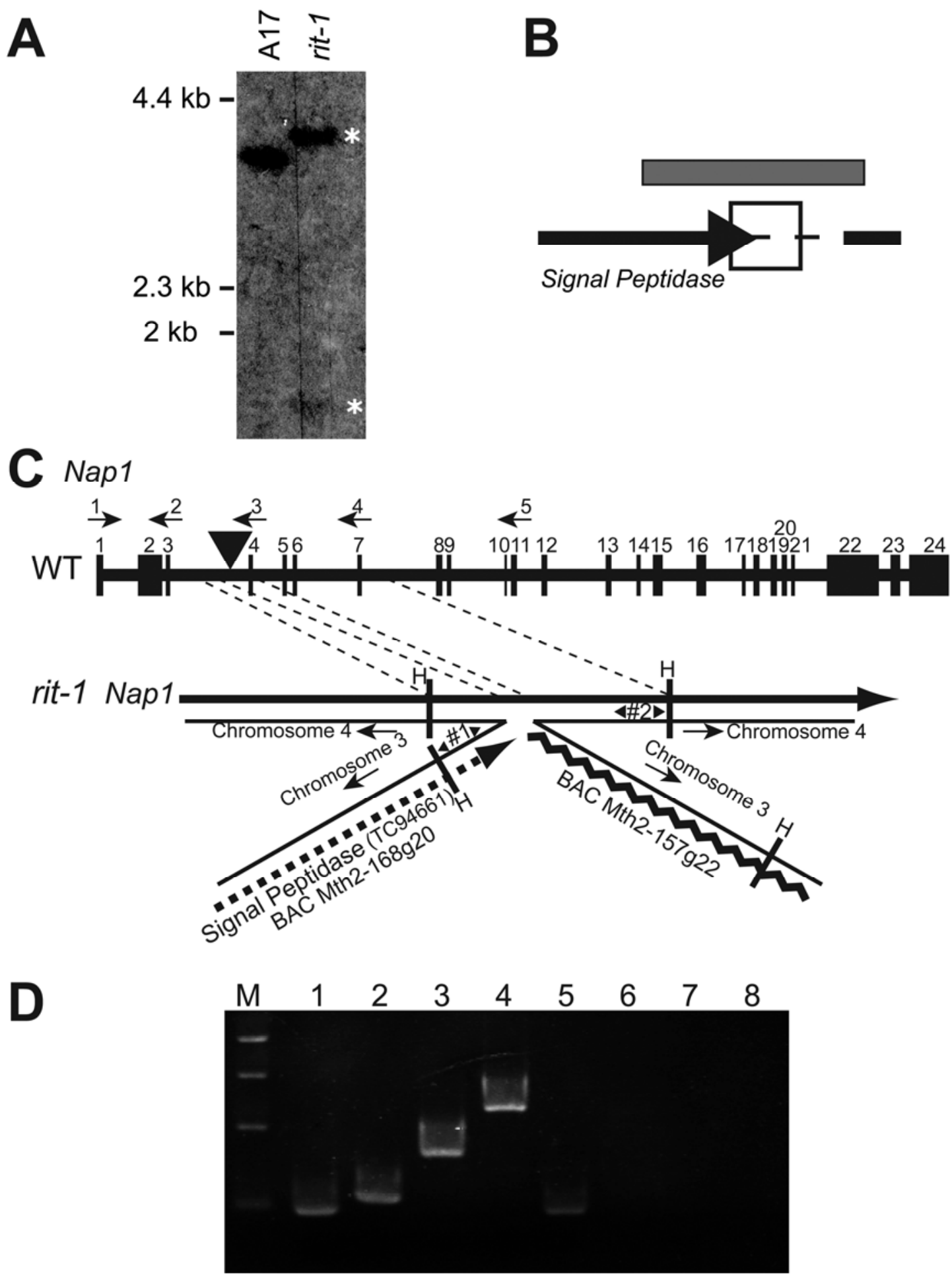

Fig. 3. Identification of the rit-1 mutation. A, DNA hybridization performed on wild-type (A17) and rit-1 genomic DNA digested with HindIII, probed with a fragment of the $3^{\prime}$ end of TC94661. The presence of two bands in the rit-1 lane, indicated with *, suggests that either an insertion or a rearrangement has occurred. B, The dark gray bar indicates the probe used, and the black box indicates the site of the suspected mutation. C, An illustration of the deletioninsertion rearrangement between chromosome 3 and 4 present in rit-1. Only the breakpoints defined by the inverse polymerase chain reaction (PCR) are shown. Based on the sequencing of HindIII-based inverse PCR products, we conclude that a fragment between Mth2-168g20 and Mth2-157g22 on chromosome 3 is inserted in the NAP1 gene on chromosome 4; however, additional rearrangements may also have occurred in this chromosome 3 fragment. \#1 and \#2 with arrowheads indicate locations of primers used for inverse PCR; H = HindIII site. D, Reverse-transcription PCR of NAP1 in Medicago truncatula reveals that only the $5^{\prime}$ end of the gene is expressed in rit-1. Lanes 1 to 4 , wild type (A17); lanes 5 to 8, rit-1; lanes 1 and 5, a PCR fragment of NAPl using primers $1+2$ in C (exon 1 to exon 3); lanes 2 and 6, using primers $1+3$ in C (exon 1 to exon 4 ); lanes 3 and 7 , using primers $1+4$ in $\mathrm{C}$ (exon 1 to exon 7); lanes 4 and 8 , using primers $1+5$ in $\mathrm{C}$ (exon 1 to exon 11 ); $\mathrm{M}$, size marker. 
The NAPl gene consists of 24 exons and contains a rare noncanonical GC-AG splice donor-acceptor structure in the fifth intron similar to that in L. japonicus NAPl (Yokota et al. 2009). The NAPl cDNA is predicted to encode a protein of 1,383 amino acids that is $77 \%$ identical to A. thaliana NAP1.

\section{Complementation of the rit-1 mutation with NAP1.}

The rearrangements in rit- 1 caused disruptions in at least two genes: TC94661 and NAP1. We tested both of these genes for their ability to complement rit-1 using transformation with Agrobacterium rhizogenes to form composite plants with

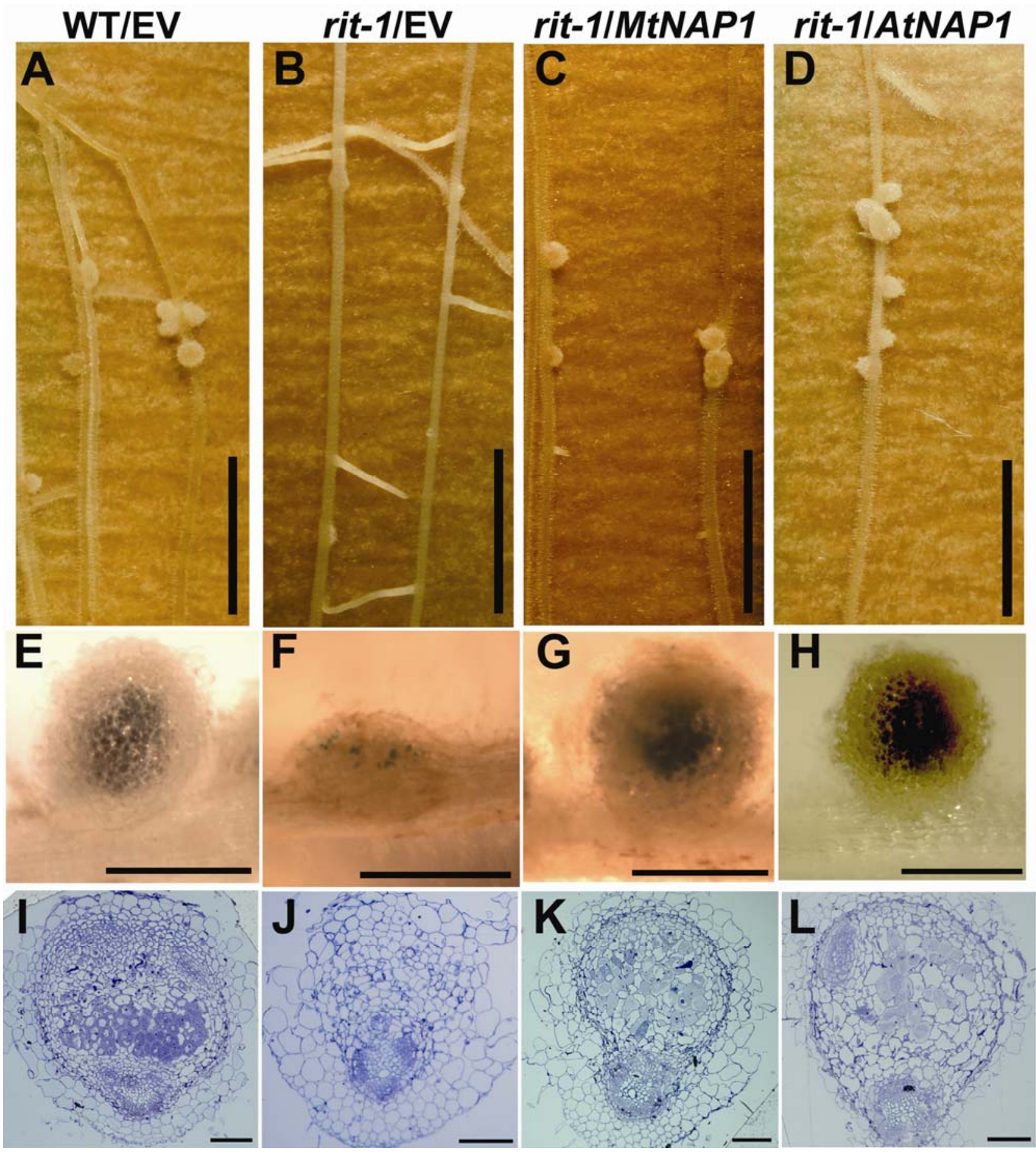

Fig. 4. Complementation of rit-1 for nodulation. Transformation of rit-1 with the NAP1 genes of Medicago truncatula and Arabidopsis thaliana allow nodulation in the mutant. A, Nodules in a wild-type plant transformed with the empty vector; B, bumps in a rit-1 mutant transformed with the empty vector; $\mathbf{C}$, nodules in a rit-1 mutant transformed with 35S-NAP1 cDNA from M. truncatula; D, nodules in a rit-1 mutant transformed with 35S-NAP1 cDNA from A. thaliana; E, wild-type nodules transformed with the empty vector contain colonized bacteria (blue staining inside the nodule); $\mathbf{F}$, rhizobia are limited to aborted infection threads associated with bumps in rit-1 transformed with the empty vector; G, nodules were successfully colonized by rhizobia in rit-1 nodules complemented with 35S-NAPI from M. truncatula; $\mathbf{H}$, nodules were successfully colonized by rhizobia in rit-1 nodules complemented with 35S-NAPI from A. thaliana; $\mathbf{I}$, thin section of a nodule on a wild-type root transformed with the empty vector; $\mathbf{J}$, thin section of a nodule from a rit-1 root transformed with the empty vector; $\mathbf{K}$, thin section of a nodule on a rit-1 root transformed with $35 S$-NAP1 from M. truncatula; $\mathbf{L}$, thin section of a nodule on a rit- 1 root transformed with 35S-NAP1 from A. thaliana. I to $\mathbf{L}$, Diffuse blue staining in the nodule reveals bacteroids within the nodule cells. The intensity of the coloration is indicative of the degree of staining rather than level of colonization. All images are from transformed roots 12 days postinoculation of Sinorhizobium meliloti 1021 hemA-LacZ. Scale bars $=1 \mathrm{~cm}$ (A to D), $500 \mu \mathrm{m}$ (E to H), and $100 \mu \mathrm{m}$ (I to L). 
transformed hairy roots. Although TC94661 was unable to complement rit-1 (data not shown), we found that transformation of $M$. truncatula NAP1 cDNA driven by the $35 \mathrm{~S}$ promoter restored normal nodulation to rit-1 (Fig. 4C). The complemented roots could accommodate bacteria within nodules (Fig. $4 \mathrm{G}$ and $\mathrm{K}$ ), whereas the rit- 1 mutant did not show infected nodules under these conditions (Fig. 4F and J). These results indicate that the mutation in NAPI was, indeed, causative of the rit- 1 nodule defect.

In order to assess whether legume $N A P 1$ has specifically evolved the capability to sustain infection-thread growth, we tested whether NAPl from Arabidopsis thaliana could complement rit-1. A. thaliana NAP1 cDNA driven by the $35 \mathrm{~S}$ promoter was able to complement rit-1 for both nodulation and bacterial infection (Fig. 4D, H, and L). From this, we infer that $N A P 1$ has a conserved function in legumes and non-legumes and that the role of NAP1 in infection-thread growth is not a unique capability of legume NAPI.

As described earlier, the rit-1 mutant shows defects in root hairs, trichomes, infection threads, and the seed coat. Agrobacterium rhizogenes transformation only allows an assessment of root-related phenotypes. We found that transformation of rit-1 with 35S-NAP1 cDNAs from both M. truncatula and Arabidopsis thaliana allowed normal root-hair growth in rit-1 roots (Fig. $5 \mathrm{~A}$ through $\mathrm{D})$. Without stable transformants, we are unable to absolutely conclude that $N A P 1$ is also responsible for the trichome and seed-coat phenotypes. However, we observed that these phenotypes cosegregated and others have shown that napl mutations in A. thaliana and L. japonicus have root-hair and trichome defects (Yokota et al. 2009; Zimmermann et al. 2004). Thus, we conclude that the mutation in the NAPl gene in rit-1 is causative of the root-hair and infection-thread defects and is also likely to be causative of the trichome and seed-coat defects.

\section{DISCUSSION}

Infection threads are unique structures in plants associated with bacterial colonization in nitrogen-fixing symbioses. They are polar-growing invaginations of the plant cell, with the cell wall matrix on the inside of the infection thread. Once initiated, the route of the infection thread within the cell is traced by the movement of nuclei (Nutman 1959) and the path through neighboring cells is predicted by alignments of the cytoskeleton, forming preinfection threads (van Brussel et al. 1992). This process has been likened to aspects of cell plate formation but, rather than a division plane forming, a tube-like intrusion devel- ops (Brewin 2004). Considering the importance of the cytoskeleton in directing cell division and cell growth (Hussey et al. 2006; Wasteneys and Galway 2003), it is predictable that infection-thread development will necessitate dynamic rearrangements in the cytoskeleton. Much work has shown that this is, indeed, the case (Esseling and Emons 2004; Takemoto and Hardham 2004).

A major function of filamentous actin (F-actin) is to guide vesicles to sites of cell growth (Hussey et al. 2006). During rhizobial colonization, redirected root-hair growth around the site of bacterial attachment and polar-growing infection threads will both require this action of F-actin, suggesting that F-actin must be dynamically regulated during rhizobial colonization. In support of this, a number of researchers have documented dynamic changes in F-actin during rhizobial colonization: Nod factor application rapidly induces the accumulation of fine actin microfilaments at the root-hair tip (de Ruijter et al. 1999; Yokota et al. 2009). This is likely to be associated with the redirection of root-hair growth and this is supported by cytochalasin treatment, which inhibits actin polymerization, which suppresses Nod factor-induced root-hair outgrowth (Miller et al. 1999). At later stages, diffuse actin microfilaments are associated with the surface of the infection thread and more dense actin microfilaments are associated with sites of infection-thread penetration across cell junctions (Davidson and Newcomb 2001).

One of the main mechanisms for dynamic F-actin regulation is through modulation by the ARP $2 / 3$ complex that nucleates actin polymerization. This mechanism is conserved across all eukaryotes. ARP2/3 is activated by the SCAR/WAVE complex which, in turn, is activated by ROP-type small GTPases (Hussey et al. 2006). Here, we have shown that a mutation in the M. truncatula ortholog of NAP1, a component of the SCAR/WAVE complex, is required for appropriate root-hair, trichome, and infection-thread growth. In A. thaliana, mutations in NAPl and several additional members of the SCAR/WAVE complex show distorted trichomes (Basu et al. 2005; Brembu et al. 2004; ElDin El-Assal et al. 2004; Frank and Smith 2002; Li et al. 2004; Mathur et al. 2003a,b; Zhang et al. 2005; Zimmermann et al. 2004). Furthermore, it has recently been reported that mutations of L. japonicus in NAP1 and PIR1, both SCAR/WAVE complex components, show similar defects in root hairs, trichomes, and infection threads as well as additional developmental defects (Yokota et al. 2009).

Considering the fact that rit-1 shows an inability to sustain infection-thread growth and, in particular, reveals swollen pro-
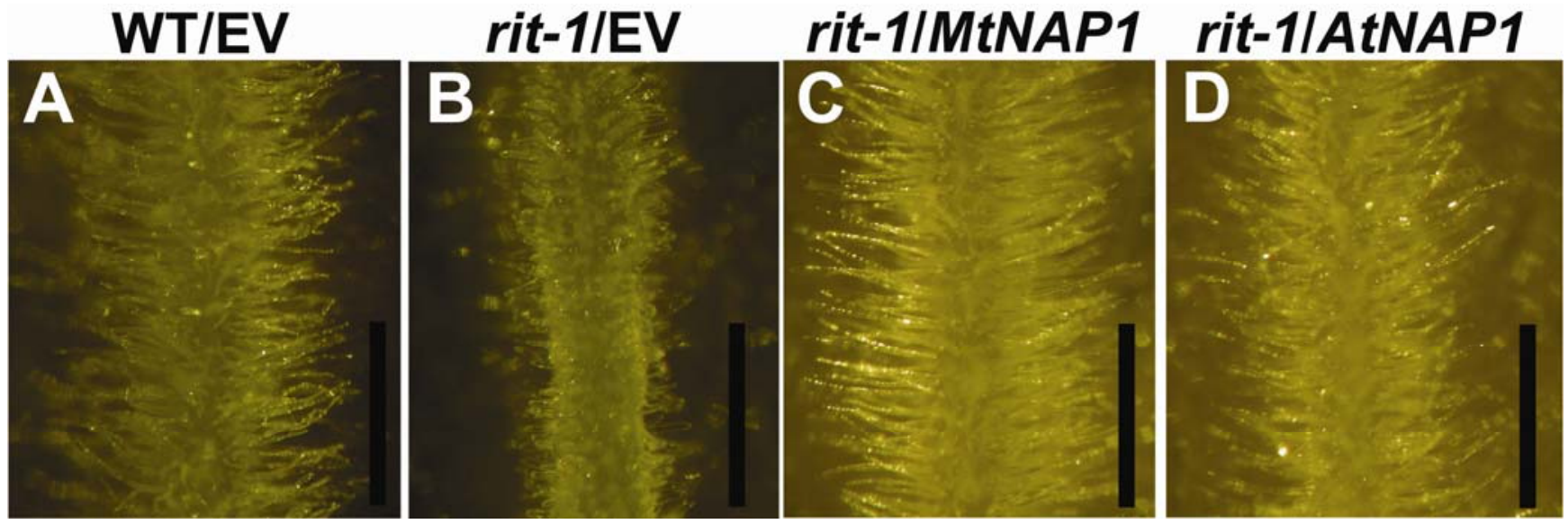

Fig. 5. Root-hair phenotype in complemented rit-1 plants. NAP1 cDNA from Medicago truncatula and Arabidopsis thaliana complement root-hair development in the rit-1 mutant. A, Wild-type (WT) root transformed with the empty vector (EV); B, rit-1 root transformed with the EV; $\mathbf{C}$, rit-1 root transformed with 35S-NAP1 cDNA from M. truncatula; D, rit-1 root transformed with 35S-NAP1 cDNA from A. thaliana. Scale bars $=1 \mathrm{~mm}$. 
trusions at infection-thread tips (Fig. 1C), we propose that $N A P 1$ is required for directing $\mathrm{F}$-actin reorganization to ensure appropriate polar growth of the infection thread. This would imply that the major function of the SCAR/WAVE complex during nodulation is directed vesicle transport to the infectionthread tip. However, Yokota and associates (2009) showed that napl and pirl mutants of L. japonicus show defects in the rapid Nod-factor-induced F-actin accumulation at the root-hair tip. This would imply that NAPI and PIRI are likely to function during Nod factor reorientation of root-hair growth. However, the infection-thread defects in napl and pirl mutants in L. japonicus are similar to those observed in rit-1: abortion of infection threads in the root-hair cells or outer cortical cells but no reported defect in Nod-factor-induced root-hair deformation. Although the ARP2/3 and SCAR/WAVE complex mutants are essential for survival in animals (Stevenson et al. 2002), it is clear that this is not the case in plants, and this may suggest a level of redundancy for this function in actin nucleation in plants. This could explain why root-hair deformation is observed in legume NAPI and PIRI mutants but the continued progression of infection-thread growth is defective.

The actin cytoskeleton is essential for many functions: it acts as a scaffold for positioning the endoplasmic reticulum, it is used for trafficking organelles (Boldogh et al. 2001), and it also mediates the recycling of endosomes and is important in formation of lamellipodia and cell motility (Vartiainen and Machesky 2004). Although the regulation of vesicle transport through the regulation of $\mathrm{F}$-actin is the most likely explanation for NAPl function during nodulation, we cannot currently exclude any of the above functions. Our research provides genetic support for the essential role of dynamic F-actin regulation during infection-thread development and provides the foundations for understanding the plant mechanisms for the activation of this unique cellular structure.

\section{MATERIALS AND METHODS}

\section{Plant growth conditions.}

$M$. truncatula $\mathrm{cv}$. Jemalong A17 was used as the wild type in all experiments described. Backcrosses of rit-1 were to A17 and mapping crosses to the ecotype A20. For plate assays, seed were treated and seedlings were inoculated with $S$. meliloti as previously described (Middleton et al. 2007).

\section{Genetic mapping.}

rit-1 $\times \mathrm{A} 20 \mathrm{~F}_{2}$ individuals were grown on soil $(50 \%$ peat or sand and 50\% John Innes no. 2 compost) in glasshouses supplemented with sodium lighting to reach a 16-h photoperiod. The trichome phenotype identified rit-1 individuals and DNA was isolated in 96-well plates using tungsten carbide beads and a mixer mill (Retsch) in $400 \mu \mathrm{l}$ of $65^{\circ} \mathrm{C}$ extraction buffer (250 mM NaCl, 25 mM EDTA [pH 8.0], 20 mM Tris-HCl [pH 7.5], and $0.5 \%$ sodium dodecyl sulfate [SDS]). Samples were incubated for $30 \mathrm{~min}$ at $65^{\circ} \mathrm{C}$, the debris pelleted, and the DNA isolated following a phenol/chloroform extraction. DNA was then precipitated using $70 \%$ ethanol and resuspended in $100 \mu \mathrm{l}$ of Tris-EDTA. DNA was diluted 10-fold before use for PCR. All genetic markers were assayed using PCR (Supplementary Table 2) and the products separated on 3 to $4 \%$ agarose gels to allow scoring.

\section{Inverse PCR, RT-PCR, and random amplification of cDNA ends.}

For inverse PCR, $1 \mu \mathrm{g}$ of rit- 1 genomic DNA was digested with HindIII, and the digested DNA was purified with a PCR purification kit (Qiagen, Crawley, U.K.). The purified DNA fragments were self-ligated with T4 DNA ligase (Promega
Corp., Chilworth, U.K.), and PCR was conducted using Phusion polymerase (New England Biolabs, Hitchin, U.K.) with the following conditions: $30 \mathrm{~s}$ of denaturation at $98^{\circ} \mathrm{C}$; followed by 35 cycles of $98^{\circ} \mathrm{C}$ for $10 \mathrm{~s}, 55^{\circ} \mathrm{C}$ for $30 \mathrm{~s}$, and $72^{\circ} \mathrm{C}$ for $3 \mathrm{~min}$; followed by a 10 -min extension at $72^{\circ} \mathrm{C}$. Primers used for inverse PCR are shown in Supplementary Table 3. Amplified fragments were purified using a PCR purification kit (Qiagen) and directly sequenced. Total RNA for RT-PCR and $5^{\prime}$ and $3^{\prime}$ random amplification of cDNA ends (RACE) were extracted from uninoculated $M$. truncatula seedlings using the RNeasy mini kit (Qiagen). The 5' and 3' untranslated region sequences of NAPl were determined by $5^{\prime}$ and $3^{\prime}$ RACE kits (Invitrogen, Paisley, U.K.), respectively.

\section{Complementation tests.}

An open reading frame of $N A P 1$ was amplified by RT-PCR and cloned into a pDONR207 donor vector (Invitrogen) using the primers MtNAP-fw (5'-GGGGACAAGTTTGTACAAA AAAGCAGGCTTCATGGCGAAGTCGAGGCAAAA-3') and MtNAP-rev (5'-GGGGACCACTTTGTACAAGAAAGCTGG GTCCTACTTGTATGCTAATGGACCAG-3'). An open reading frame of $A$. thaliana NAPl was amplified by RT-PCR using the primers AtNAP-fw (5'-GGGGACAAGTTTGTACAAAAA AGCAGGCTTCGAATTAATGGCGAATTCT-3') and AtNAPrev (5'-GGGGACCACTTTGTACAAGAAAGCTGGGTCTG GGAGTGTTGTTACTTAGTTATGCTGTTT-3'). Constructs for complementation tests were prepared by Gateway LR reactions between the pDONR207-MtNAP1 and pDONR207-AtNAP1 entry vectors and the destination vector pK7WG2D (Karimi et al. 2002). Composite plants with transformed roots were generated according to the protocol of Boisson-Dernier and associates (2001) using the Agrobacterium rhizogenes strain ARqua1 (Quandt et al. 1993) harboring the constructs of interest. Kanamycin at $25 \mu \mathrm{g} / \mathrm{ml}$ was used to select for roots containing the constructs. Once hairy root systems were established, they were transferred to growth pouches as described by Gleason and associates (2006). Roots were inoculated with $S$. meliloti 1021 and scored for nodule formation after 12 days.

\section{SYTO13 staining of nodules.}

SYTO13 staining was carried out as described (Haynes et al. 2004). Nodules were cut longitudinally, stained, and then placed in chambered coverslips (Nalgene/Nunc International, Hereford, U.K.). Images were obtained using a Leica SP2 confocal, with inverted microscope, using the 488-nm Argon ion laser for SYTO13 visualization (excitation $488 \mathrm{~nm}$, emission 509) and the 543-nm HeNe laser for visualization of autofluorescence (excitation $543 \mathrm{~nm}$, emission $560 \mathrm{~nm}$ ).

\section{Acetylene reduction assays.}

Nodule samples were placed in a blood tube (Vacutainer; Becton-Dickinson, Oxford, U.K.) and sealed with a rubber lid and parafilm. Acetylene $(0.15 \mathrm{ml})$ was injected and samples were incubated for $2 \mathrm{~h}$ at room temperature. The amount of ethylene produced was quantified by comparison with an ethylene standard. A gas chromatograph equipped with a hydrogen flame ionization detector was used. The column was $1.5 \mathrm{~m}$ long and $3.25 \mathrm{~mm}$ in diameter and packed with Porapak N.

\section{DNA hybridizations.}

Crosslinked membranes or BAC filters (Sanger Centre, Hinxton, U.K.) were used for the probe hybridizations. Membranes and filters were prehybridized in $25 \mathrm{ml}$ of hybridization buffer $(0.5 \mathrm{M}$ sodium phosphate, $1 \mathrm{mM}$ EDTA, and $7 \%$ SDS [wt/vol], $\mathrm{pH} 7.4$ ) for $2 \mathrm{~h}$ at $65^{\circ} \mathrm{C}$ to prevent nonspecific binding of the probe. The buffer was replaced by single-strand DNA probes with incorporated ${ }^{32} \mathrm{P}$ dCTP (Rediprime II kit, GE 
Healthcare, Little Chalfont, U.K.), and hybridization was allowed to occur overnight at $65^{\circ} \mathrm{C}$. Blots were washed twice using wash solution $(0.1 \%$ SDS, $0.5 \times \mathrm{SSC}[1 \times \mathrm{SSC}$ is $0.15 \mathrm{M}$ $\mathrm{NaCl}$ plus $0.015 \mathrm{M}$ sodium citrate]) for $15 \mathrm{~min}$ at $65^{\circ} \mathrm{C}$, then wrapped and exposed to film or storage phosphor screen.

\section{ENOD11-GUS assay.}

Fresh root samples were ground in $200 \mathrm{ml}$ of extraction buffer $(50 \mathrm{mM}$ sodium phosphate, $10 \mathrm{mM}$ EDTA, $0.1 \%$ [vol/vol] Triton X-100, 0.1\% [vol/vol] sarcosyl, and $10 \mathrm{mM} \beta$ mercaptoethanol) on ice. Samples were pelleted at $12,000 \mathrm{rpm}$ and $4^{\circ} \mathrm{C}$. Total proteins were quantified using Bradford reagent and 10 to $20 \mu \mathrm{g}$ of total protein diluted with extraction buffer containing $1 \mathrm{mM}$ methyl-umbelliferone glucuronide to a volume of $200 \mu \mathrm{l}$. Samples were incubated for $1 \mathrm{~h}$ at $37^{\circ} \mathrm{C}$ and $40-\mu \mathrm{l}$ aliquots added to $1 \mathrm{ml}$ of stop buffer $\left(0.2 \mathrm{M} \mathrm{Na}_{2} \mathrm{CO}_{3}\right)$. Aliquots $(100 \mu \mathrm{l})$ of stopped reactions were assayed for production of 4-methyl umbelliferone using a SAFIRE (Tecan Instruments, Theale, U.K.) plate reader.

\section{ACKNOWLEDGMENTS}

We thank K. Findlay and S. Bunnewell for help with tissue sectioning and electron microscopy, J. Rogers and her team at the Welcome Trust Sanger Centre for genome sequence data, and N. Young for help with genetic marker development. This work was supported by a European Research Council grant to G. E. D. Oldroyd, the European Union (MRTNCT-2006-035546), and by a grant in aid from the BBSRC to G. E. D. Oldroyd and J. A. Downie. G. Morieri was supported by European Union grant (MRTN-CT-2006-035546).

\section{LITERATURE CITED}

Ardourel, M., Demont, N., Debelle, F., Maillet, F., de Billy, F., Prome, J. C., Denarie, J., and Truchet, G. 1994. Rhizobium meliloti lipooligosaccharide nodulation factors: Different structural requirements for bacterial entry into target root hair cells and induction of plant symbiotic developmental responses. Plant Cell 6:1357-1374.

Arrighi, J. F., Godfroy, O., de Billy, F., Saurat, O., Jauneau, A., and Gough, C. 2008. The RPG gene of Medicago truncatula controls Rhizobiumdirected polar growth during infection. Proc. Natl. Acad. Sci. U.S.A. 105:9817-9822.

Basu, D., Le, J., El-Essal Sel, D., Huang, S., Zhang, C., Mallery, E. L., Koliantz, G., Staiger, C. J., and Szymanski, D. B. 2005. DISTORTED3/ SCAR2 is a putative arabidopsis WAVE complex subunit that activates the Arp2/3 complex and is required for epidermal morphogenesis. Plant Cell 17:502-524.

Boisson-Dernier, A., Chabaud, M., Garcia, F., Becard, G., Rosenberg, C., and Barker, D. G. 2001. Agrobacterium rhizogenes-transformed roots of Medicago truncatula for the study of nitrogen-fixing and endomycorrhizal symbiotic associations. Mol. Plant-Microbe Interact. 14:695-700.

Boldogh, I. R., Yang, H. C., Nowakowski, W. D., Karmon, S. L., Hays, L. G., Yates, J. R., 3rd, and Pon, L. A. 2001. Arp2/3 complex and actin dynamics are required for actin-based mitochondrial motility in yeast. Proc. Natl. Acad. Sci. U.S.A. 98:3162-3167.

Brembu, T., Winge, P., Seem, M., and Bones, A. M. 2004. NAPP and PIRP encode subunits of a putative wave regulatory protein complex involved in plant cell morphogenesis. Plant Cell 16:2335-2349.

Brewin, N. J. 2004. Plant cell wall remodelling in the Rhizobium-legume symbiosis. Crit. Rev. Plant Sci.23:293-316.

Davidson, A.L., and Newcomb, W. 2001. Changes in actin microfilament arrays in developing pea root nodule cells. Can. J. Bot. 79:767-776.

de Ruijter, N. C. A., Bisseling, T., and Emons, A. M. C. 1999. Rhizobium nod factors induce an increase in sub-apical fine bundles of actin filaments in Vicia sativa root hairs within minutes. Mol. Plant-Microbe Interact. 12:829-832.

El-Din El-Assal, S., Le, J., Basu, D., Mallery, E. L., and Szymanski, D. B. 2004. DISTORTED2 encodes an ARPC2 subunit of the putative Arabidopsis ARP2/3 complex. Plant J. 38:526-538.

Esseling, J. J., and Emons, A. M. 2004. Dissection of Nod factor signalling in legumes: Cell biology, mutants and pharmacological approaches. J. Microsc. 214:104-113.

Esseling, J. J., Lhuissier, F. G., and Emons, A. M. 2003. Nod factorinduced root hair curling: Continuous polar growth towards the point of nod factor application. Plant Physiol. 132:1982-1988.

Frank, M. J., and Smith, L. G. 2002. A small, novel protein highly conserved in plants and animals promotes the polarized growth and division of maize leaf epidermal cells. Curr. Biol. 12:849-853.

Gleason, C., Chaudhuri, S., Yang, T., Munoz, A., Poovaiah, B. W., and Oldroyd, G. E. 2006. Nodulation independent of rhizobia induced by a calcium-activated kinase lacking autoinhibition. Nature 441:1149-1152.

Haynes, J. G., Czymmek, K. J., Carlson, C. A., Veereshlingam, H., Dickstein, R., and Sherrier, D. J. 2004. Rapid analysis of legume root nodule development using confocal microscopy. New Phytol. 163:661668.

Hussey, P. J., Ketelaar, T., and Deeks, M. J. 2006. Control of the actin cytoskeleton in plant cell growth. Annu. Rev. Plant Biol. 57:109-125.

Journet, E. P., El-Gachtouli, N., Vernoud, V., de Billy, F., Pichon, M., Dedieu, A., Arnould, C., Morandi, D., Barker, D. G., and GianinazziPearson, V. 2001. Medicago truncatula ENOD11: A novel RPRPencoding early nodulin gene expressed during mycorrhization in arbuscule-containing cells. Mol. Plant-Microbe Interact. 14:737-748.

Karimi, M., Inze, D., and Depicker, A. 2002. GATEWAY vectors for Agrobacterium-mediated plant transformation. Trends Plant Sci. 7:193-195.

Kiss, E., Olah, B., Kalo, P., Morales, M., Heckmann, A. B., Borbola, A., Lozsa, A., Kontar, K., Middleton, P., Downie, J. A., Oldroyd, G. E., and Endre, G. 2009. LIN, a novel type of U-box/WD40 protein, controls early infection by rhizobia in legumes. Plant Physiol. 151:1239-1249.

Li, Y., Sorefan, K., Hemmann, G., and Bevan, M. W. 2004. Arabidopsis NAP and PIR regulate actin-based cell morphogenesis and multiple developmental processes. Plant Physiol. 136:3616-3627.

Limpens, E., Franken, C., Smit, P., Willemse, J., Bisseling, T., and Geurts, R. 2003. LysM domain receptor kinases regulating rhizobial Nod factor-induced infection. Science 302:630-633.

Mathur, J., Mathur, N., Kernebeck, B., and Hulskamp, M. 2003a. Mutations in actin-related proteins 2 and 3 affect cell shape development in Arabidopsis. Plant Cell 15:1632-1645.

Mathur, J., Mathur, N., Kirik, V., Kernebeck, B., Srinivas, B. P., and Hulskamp, M. 2003b. Arabidopsis CROOKED encodes for the smallest subunit of the ARP2/3 complex and controls cell shape by region specific fine F-actin formation. Development 130:3137-3146.

Middleton, P. H., Jakab, J., Penmetsa, R. V., Starker, C. G., Doll, J., Kalo, P., Prabhu, R., Marsh, J. F., Mitra, R. M., Kereszt, A., Dudas, B. VandenBosch, K., Long, S. R., Cook, D. R., Kiss, G. B., and Oldroyd, G. E. 2007. An ERF transcription factor in Medicago truncatula that is essential for Nod factor signal transduction. Plant Cell 19:12211234

Miller, D., de Ruijter, N., Bisseling, T., and Emons, A. M. 1999. The role of actin in root hair morphogenesis: Studies with lipochito-oligosaccharide as a growth stimulator and cytochalasin as an actin perturbing drug. Plant J. 17:141-154.

Nutman, P. S. 1959. Some observations on root-hair infection by nodule bacteria. J. Exp. Bot. 10:250-263.

Oldroyd, G. E., and Downie, J. A. 2008. Coordinating nodule morphogenesis with rhizobial infection in legumes. Annu. Rev. Plant Biol. 59:519-546.

Ooki, Y., Banba, M., Yano, K., Maruya, J., Sato, S., Tabata, S., Saeki, K., Hayashi, M., Kawaguchi, M., Izui, K., and Hata, S. 2005. Characterization of the Lotus japonicus symbiotic mutant lot 1 that shows a reduced nodule number and distorted trichomes. Plant Physiol. 137:1261-1271.

Quandt, H. J., Puhler, A., and Broer, I. 1993. Transgenic root-nodules of Vicia-Hirsuta - a fast and efficient system for the study of gene-expression in indeterminate-type nodules. Mol. Plant-Microbe Interact. 6:699706.

Sandal, N., Petersen, T. R., Murray, J., Umehara, Y., Karas, B., Yano, K., Kumagai, H., Yoshikawa, M., Saito, K., Hayashi, M., Murakami, Y., Wang, X., Hakoyama, T., Imaizumi-Anraku, H., Sato, S., Kato, T., Chen, W., Hossain, M. S., Shibata, S., Wang, T. L., Yokota, K., Larsen, K., Kanamori, N., Madsen, E., Radutoiu, S., Madsen, L. H., Radu, T. G., Krusell, L., Ooki, Y., Banba, M., Betti, M., Rispail, N., Skot, L., Tuck, E., Perry, J., Yoshida, S., Vickers, K., Pike, J., Mulder, L., Charpentier, M., Muller, J., Ohtomo, R., Kojima, T., Ando, S., Marquez, A. J., Gresshoff, P. M., Harada, K., Webb, J., Hata, S., Suganuma, N., Kouchi, H., Kawasaki, S., Tabata, S., Hayashi, M., Parniske, M., Szczyglowski, K., Kawaguchi, M., and Stougaard, J. 2006. Genetics of symbiosis in Lotus japonicus: Recombinant inbred lines, comparative genetic maps, and map position of 35 symbiotic loci. Mol. PlantMicrobe Interact. 19:80-91.

Smit, P., Limpens, E., Geurts, R., Fedorova, E., Dolgikh, E., Gough, C., and Bisseling, T. 2007. Medicago LYK3, an entry receptor in rhizobial nodulation factor signaling. Plant Physiol. 145:183-191.

Stevenson, V., Hudson, A., Cooley, L., and Theurkauf, W. E. 2002. Arp2/3dependent pseudocleavage furrow assembly in syncytial Drosophila embryos. Curr. Biol. 12:705-711. 
Szymanski, D. B. 2005. Breaking the WAVE complex: The point of Arabidopsis trichomes. Curr. Opin. Plant Biol. 8:103-112.

Takemoto, D., and Hardham, A. R. 2004. The cytoskeleton as a regulator and target of biotic interactions in plants. Plant Physiol. 136:38643876.

Tansengco, M. L., Hayashi, M., Kawaguchi, M., Imaizumi-Anraku, H., and Murooka, Y. 2003. crinkle, a novel symbiotic mutant that affects the infection thread growth and alters the root hair, trichome, and seed development in Lotus japonicus. Plant Physiol .131:1054-1063.

Tansengco, M. L., Imaizumi-Anraku, H., Yoshikawa, M., Takagi, S., Kawaguchi, M., Hayashi, M., and Murooka, Y. 2004. Pollen development and tube growth are affected in the symbiotic mutant of Lotus japonicus, crinkle. Plant Cell Physiol. 45:511-520.

Temnykh, S., DeClerck, G., Lukashova, A., Lipovich, L., Cartinhour, S., and McCouch, S. 2001. Computational and experimental analysis of microsatellites in rice (Oryza sativa L.): Frequency, length variation, transposon associations, and genetic marker potential. Genome Res. 11:1441-1452.

Thoquet, P., Gherardi, M., Journet, E. P., Kereszt, A., Ane, J. M., Prosperi, J. M., and Huguet, T. 2002. The molecular genetic linkage map of the model legume Medicago truncatula: An essential tool for comparative legume genomics and the isolation of agronomically important genes. BMC Plant Biol. 2:1.

van Brussel, A. A. N., Bakhuizen, R., Vanspronsen, P. C., Spaink, H. P., Tak, T., Lugtenberg, B. J. J., and Kijne, J. W. 1992. Induction of preinfection thread structures in the leguminous host plant by mitogenic lipooligosaccharides of Rhizobium. Science 257:70-72
Vartiainen, M. K., and Machesky, L. M. 2004. The WASP-Arp2/3 pathway: Genetic insights. Curr. Opin. Cell Biol. 16:174-181.

Wasteneys, G. O., and Galway, M. E. 2003. Remodeling the cytoskeleton for growth and form: An overview with some new views. Annu. Rev. Plant Biol. 54:691-722.

Yano, K., Shibata, S., Chen, W. L., Sato, S., Kaneko, T., Jurkiewicz, A. Sandal, N., Banba, M., Imaizumi-Anraku, H., Kojima, T., Ohtomo, R., Szczyglowski, K., Stougaard, J., Tabata, S., Hayashi, M., Kouchi, H., and Umehara, Y. 2009. CERBERUS, a novel U-box protein containing WD-40 repeats, is required for formation of the infection thread and nodule development in the legume-Rhizobium symbiosis. Plant J. 60:168-180.

Yokota, K., Fukai, E., Madsen, L. H., Jurkiewicz, A., Rueda, P., Radutoiu, S., Held, M., Hossain, M. S., Szczyglowski, K., Morieri, G., Oldroyd, G. E., Downie, J. A., Nielsen, M. W., Rusek, A. M., Sato, S., Tabata, S. James, E. K., Oyaizu, H., Sandal, N., and Stougaard, J. 2009. Rearrangement of actin cytoskeleton mediates invasion of Lotus japonicus roots by Mesorhizobium loti. Plant Cell 21:267-284.

Zhang, X., Dyachok, J., Krishnakumar, S., Smith, L. G., and Oppenheimer, D. G. 2005. IRREGULAR TRICHOME BRANCH1 in Arabidopsis encodes a plant homolog of the actin-related protein $2 / 3$ complex activator Scar/WAVE that regulates actin and microtubule organization. Plant Cell 17:2314-2326.

Zimmermann, I., Saedler, R., Mutondo, M., and Hulskamp, M. 2004. The Arabidopsis GNARLED gene encodes the NAP125 homolog and con trols several actin-based cell shape changes. Mol. Genet. Genomics 272:290-296 